\title{
Radioecology's coming of age on the spot
}

\author{
F. Bréchignac ${ }^{1,2}$ \\ ${ }^{1}$ Institute of Radioprotection and Nuclear Safety (IRSN), Direction General, Centre of \\ Cadarache, Blg. 229, BP. 1, 13115 St Paul-lez-Durance Cedex, France \\ ${ }^{2}$ International Union of Radioecology (IUR), Secretariat at IRSN-DG, Centre of Cadarache, \\ Blg. 229, BP. 1, 13115 St Paul-lez-Durance Cedex, France
}

\begin{abstract}
After a period of scepticism about the future of radioecology due to post Chernobyl political trends and decisions, recent events (worldwide nuclear renaissance, Fukushima accident) demonstrate that the discipline is not only still alive but definitely needed, perhaps more than ever. However, given its long standing anthropocentric view over the environment, it has for a long time been bound exclusively to human radioprotection needs. It is argued that moving toward a more integrated eco-centric view over the environment is the clue for radioecology to reach full maturity as a stand-alone discipline, a movement which does not prevent continuing its contribution to feed human radioprotection.
\end{abstract}

\section{INTRODUCTION}

In 2002, in Monaco, at one earlier conference of this series, some of you may remember the article of a Journalist from a famous scientific Journal who followed the first debates on protection of the environment from radiation. The title said "Radioecology's coming of age, or its last gasp?" (Stone, 2002). The author expressed strong scepticism over the future of radioecology, an attitude which was indeed largely spread across many places 10 years ago, even within organisations and universities hosting well known radioecology research teams... and not mentioning those who even proposed to ban the word...

My talk to introduce this conference therefore is dedicated to defend the case that radioecology is not dead. It is not about to die, but its maturity is questioned, and this was already the case 10 years ago.

Radioecology deserves attention, probably more than ever, because the sustainability of using nuclear energy and radioactivity for civilian purposes needs to be grounded to societal acceptance. Societal acceptance in turn is highly dependent on the transparent explanation of risks and the demonstration that continuous effort is dedicated to close uncertainties with appropriate knowledge and understanding. The unfortunate occurrence of the nuclear disaster in Japan and the diverse political reactions we currently observe just come to strengthen this analysis.

With respect to the Fukushima's environmental impact, it is far too early to elaborate scientific interpretation and analysis as data availability is still very scarce. What is known already, however, is that such an impact will be long-lasting. Some Japanese colleagues will hopefully be more appropriate during this conference to provide initial reporting on the tragic succession of events and their consequences.

But another consequence from the incident which we must address is that such an event challenges the fields of Radioecology and Environmental Radioactivity. The main question to our scientific community is about our level of excellence in describing, explaining, anticipating and mastering the environmental risks. Do we have the right and optimal answers to the many immediate and longer term problems faced by our Japanese colleagues dealing with the contamination spread over the territories and affecting the population? Is our scientific understanding ripe enough to anticipate what will the 
long-term impact of the contamination on the environment be (land and sea)? It is the Radioecology's coming of age which is on the spot, and today this challenge is urged for three main reasons which I will attempt to develop further.

- The first reason refers to the political recognition of radioecology, and emerges from recent history, until March 2011, which led to the international context of 'nuclear renaissance' (the subtitle of this conference), with decisions spreading around the world to build new nuclear power plants for electric power generation. Obviously, Fukushima has already altered this trend in some places, but not in others as we can observe, similarly in fact as for Chernobyl 25 years ago, making it difficult to do any prognostic at this stage. But what remains unaltered is the driver to this renaissance: a will to overcome the growing needs for energy with an alternative to oil. This large energetic resource is now starting to become scarce as compared to the ever growing demand, and it is responsible for deleterious climatic impact due to atmospheric $\mathrm{CO}_{2}$ enrichment. It is worth therefore noting that this renaissance is quite environmentally relevant.

- The second reason stems from a long-standing dominance of an exclusively anthropocentric attitude in developing radioecology. This is rooted in an old philosophical paradigm of human technology dominance over nature, which the unfortunate nuclear accident at the Fukushima Daiichi power plant challenges today. Such an attitude has much influenced the scientific approaches and prediction tools towards environmental risk assessment of radiation.

- Finally, the coming of age of radioecology depends on its capacity to move on to a more eco-centric attitude, which means leaving the status of a subsidiary to human radioprotection only. Essentially, this means to better balance efforts dedicated to transfer and effects studies, over populations of all life species interacting in ecosystems (including human). Sustainability of all forms of life on the planet, and not only that of human beings, has become a general issue which urges to master the risk associated to environmental stressors and toxicants, including radionuclides. More eco-centrism will help radioecology to be recognized as a self-standing risk assessment discipline on its own, exactly in the spirit that its founders had in mind when they chose its name, some 60 years ago or so.

\section{HISTORICAL PERSPECTIVE: WHAT LEVEL OF POLITICAL RECOGNITION IN RADIOECOOLOGY?}

R\&D funding in Radioecology has been considerably boosted twenty five years ago by the Chernobyl accident. Facing the urgency, radioecologists were solicited primarily to assess the risks to humans from living in contaminated territories where agricultural products were grown to feed the population, but also to work out countermeasure strategies and techniques capable of mitigating such risks. Especially in Europe much impacted, important budgets have been committed for about 15 years by the European Commission to stimulate R\&D and the advancement of scientific knowledge.

During the decade which followed, however, this substantial financial support vanished out together with the post-Chernobyl political movement of several western countries to withdraw from nuclear energy production, except in a few countries. Some detractors of radioecology gained stronger voice arguing that the scientific knowledge accumulated so far was good enough to adequately deal with any radio-contamination of the environment, and that public money would be more appropriately spent elsewhere. As a consequence, a number of radioecology laboratories did not survive, and several unique research facilities and large scale programs were cancelled out within less than a decade. During the more recent years finally, a worldwide ambiance of nuclear renaissance prevailed, up to March 2011, as a meaningful response to solving the growing needs for energy. Throughout the world, we hear of various initiatives to re-establish radioecology expertise and laboratories.

A lesson from this historical background relates to the necessity of ensuring continuity in funding irrespective of the short-term political changes most sensitive to media pressure. Indeed, irrespective of the dominant political view, society will require radioecology as long as nuclear activities are going 


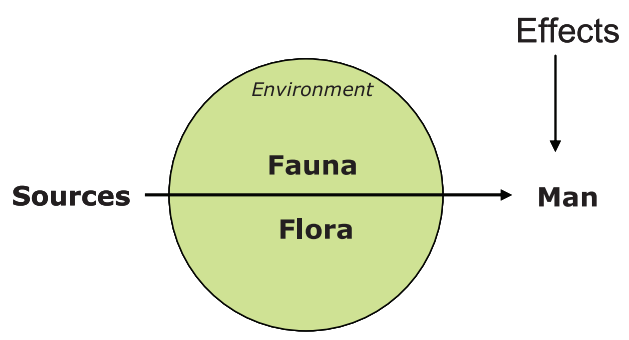

Linear Transfers

Figure 1. The anthropocentric view on radioecology as supporting human radioprotection.

on, to make sure that the associated risks are tackled and properly mastered. Such an objective can only be fulfilled with a sustainable and continuous rate of funding. Short-term variations in funding are very deleterious to research efficiency: a good research team and the related expertise takes more than one decade to be constructed and led to excellence; radioactivity specialized experimental facility are complex because highly demanding in terms of safety, and they need long-term exploitation to be brought about to data production. As a consequence, even a short duration decline in funding is much destructive of research capacity.

It is then highly desirable to think of a mechanism that would subordinate the funding of research on risks to the development of any industrial activity promoting such risks. Certainly, it could also be made such as not to impair the necessary independence status of any risk focused science. It is important to stress here that the same situation applies to other nearby scientific fields contributing to mastering the risk associated to industrial activities such as agro-chemistry, pharmaceutics, mining, etc...

\section{ANTHROPOCENTRISM: THE HISTORICAL DRIVER TO OUR RELATIONSHIP WITH NATURE}

Forces of nature are known since the beginning of humankind. This everlasting confrontation of human against an often hostile environment forced a philosophy of dominance over nature, which has often been referred to as the driver for the unique and remarkable development of the human population within the biosphere, thanks to technology development. Human intelligence, which arguably holds the top spot within the life kingdom, has strived to ever smarter technologies that provide the feeling, sometimes the belief, that forces of nature can be technologically mastered. However, even the brightest technologies, such as a nuclear reactor with its built-in high level of safety design, can occasionally be easily impaired by an unexpected natural event and cause widespread detrimental impacts, irrespective of the technological development level achieved. This challenges the dominance paradigm, also known as anthropocentrism, that has greatly influenced the relationships between humankind and nature.

For example, when moving from the causes to the consequences on life from environmental radioactivity, one observes that radioecology has also evolved primarily along an anthropocentric goal which resulted in focusing on transfer of radioactivity through the environment to man (Figure 1). Even in the recent move driven by environment protection purposes, ecological risk assessment procedures currently designed to target now animal and plant species are still directly inspired from those targeting protection of the human species. In particular, there is quite limited account, if any, for the interactions between all such life forms. From this perspective, this is again rooted in an anthropocentric view, and this is certainly contributing to the observation that, 25 years after the Chernobyl disaster, the long-term burden to life of the radioactive contamination of the environment is still highly controversial. There is 
no exception for radiation impacts as they are to evolve due to the incident at the Fukushima Daiichi nuclear power plant, if we don't take appropriate measures to improve the situation.

Controversy stems from our reluctance to consider in a more integrated manner the contaminated environment and the resident interacting species which live in. Better integration would first acknowledge that the negative potential radiological impact in Chernobyl's environment is actually superimposed with a positive impact on wildlife due to the removal of human presence some 20-25 years ago, and that consequently, it is only the net effect that we observe in situ. This is obviously puzzling proper interpretation.

Furthermore, today's risk assessment methodology does not meet the integration requirement as set in the overall objectives of environment protection: to protect ecosystem's structure (biodiversity) and functions (life support and the provision of services to humankind). Indeed, such a methodology still considers more the effects on the subsystem components taken in isolation than effects on the overall system. It therefore looks primarily at effects on DNA, cells, organs, and individual organisms (as for humans), where effects are indeed experimentally observed at relatively low doses. But in the absence of a more integrated approach, featuring the world of interactions in ecosystems, there are many difficulties in grasping what it could mean when such components are replaced within the overall real system, i.e. within larger scales of biological organisation (populations, communities and ecosystems) and time (through successive generations). This is actually what ultimately matters. It is worthwhile noting that in other fields of environmental risk management such as biodiversity, climate change, fisheries and forestry, such a movement towards a more eco-centric and integrated direction is already engaged at international level.

Lack of integration prevents to adequately grasp long-term and often non-direct impacts in ecosystems, as a result of the direct radiation effects in organisms. One specific aspect I would like to highlight today relates to the potential impact on biodiversity and its relationship to the resistance and/or the resilience of ecosystems. Resistance is the built-in ability of an ecosystem to resist pressure to change, as induced by a toxicant stressor, for example. Similarly, resilience is defined as the ability of the ecosystem to return back to its previous equilibrium status. This is an aspect certainly deserving more serious consideration when attempting to identify effects thresholds, since damage to an ecosystem would most likely depend on its resistance and resilience status.

What is important here is that nature, or better say the "biosphere", is a complex system. Making it very short, theory explains that complex systems exhibit a so-called "chaotic behaviour" together with emerging properties (like resistance and resilience, precisely) due to the multiple retro-action feed back at work between the many system's components. Upon external pressure to change, as promoted by a stressor, complex systems usually exhibit a tendency for resistance and resilience, and sometimes, when exceeding a threshold, they abruptly shift towards a different meta-stable equilibrium. Such behaviours have been repeatedly described and documented for ecosystems and I see no reason why radiationinduced stress would not be concerned as well.

\section{MORE ECO-CENTRISM: THE CLUE FOR RADIOECOLOGY RECOGNITION AS A SELF-STANDING SCIENTIFIC DISCIPLINE}

Hopefully, this conference should take the stock of the situation, and help revealing where are uncertainties still lying, what aspects we should improve, and where are priorities. This will be the task of the newly built European network of excellence in radioecology, and its further deployment at full international scale that IUR will promote, a process aimed at designing a common and harmonized strategic research agenda. I do not want to anticipate what will be the detailed research directions emerging from this process, but I would like to propose a general framework as an aid to structure the various actions which would ultimately drive radioecology to full maturity.

When referring to the biosphere as a complex system with particular concern over the long-term burden to life promoted by environmental contamination with radionuclides, it is no longer possible to hold a pure anthropocentric view, because humans are becoming isolated from the overall system. 


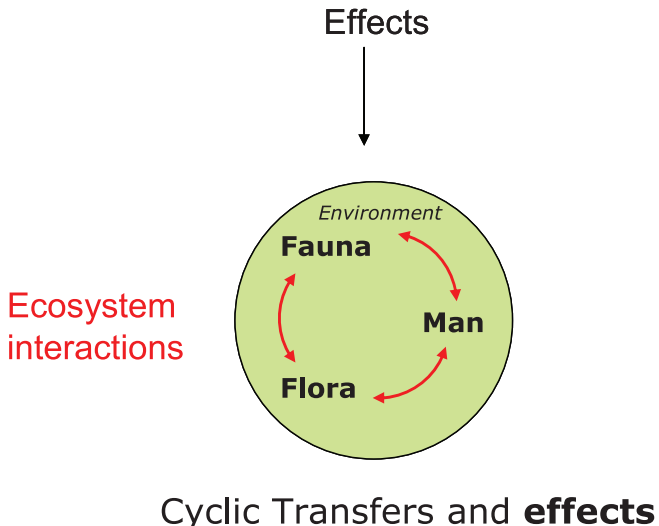

Figure 2. The eco-centric view on Radioecology as supporting ecological risk assessment.

Humans are part of the system; we influence the system and are also influenced by the system, exactly as other species are. Unravelling adverse effects from radiation along an eco-centric view (Figure 2) is acknowledging that all life forms are necessarily interacting and therefore linked altogether (as for food production/consumption, for example), and that any harm to one species will necessarily propagate also through such interactions.

Today's radioecology has actually started to move beyond a pure anthropocentric view by addressing impact on animals and plants as independent organismal entities. It is not yet able however to address them also through an ecosystem perspective featuring their population and communities assemblies where all life support processes are actually grounded.

Future radioecology shall be capable of assessing the overall ecological risks which may affect the long-term survival, or well-being, of animals, plants and humans, taken as populations which interact one with each other. The keywords here are "linkage" and "integration". Linkage: because the research focus remains fragmented over some parts of the system which tend to restrict proper scientific knowledge. Integration: because the system behavior cannot be obtained from simply summing up the behaviors of its parts.

\section{CONCLUSION}

Of course, there are still uncertainties or deficiencies in the field of traditional radioecology to support human radioprotection (transfer factors defined in quite theoretical conditions, shortage of innovative solutions to soil decontamination, etc...), but my point today is to highlight that radioecology cannot reach full maturity if it remains confined to a subsidiary role to support another field (human radioprotection). I want to encourage Radioecology to aim at much more "ecological" ambition, to establish the right long-term foundation for environment radioprotection, a goal which of course does not come in contradiction with further supporting human radioprotection.

I know that the scientific program which has been set up by Mc Master University together with IRSN, NRPA, and in collaboration with IAEA, IUR, ICRP, NEA/OECD and the Journal of Environmental Radioactivity is already reflecting on the on-going deployment of this ambition.

Finally, I wish you all that this conference will provide you with radioecology friendship, first of all, to strengthen our community, and I am especially thinking of our Japanese radioecologists colleagues, but also with fruitful discussions, innovative gatherings, and the rewarding feeling, if not the demonstration, that we are all making good progress.

\section{References}

[1] Stone R. (2002) Radioecology's coming of age - or its last gasp? Science 297:1800-1801. 